\title{
Characterization of HTS Coils for Superconducting Rotating Electric Machine Applications: Challenges, Material Selection, Winding Process, and Testing
}

\author{
Giuseppe Messina, Mohammad Yazdani-Asrami, Member, IEEE, Fabrizio Marignetti, Senior Member, IEEE, \\ and A. della Corte, Fellow, IEEE
}

\begin{abstract}
The second-generation high temperature superconducting tapes (2G-HTS) such as the REBCO coated conductors (CC) are known for their strong mechanical properties and high current carrying capacity with low AC losses compared with first-generation HTS tapes as well as low temperature superconductors. Therefore, they seem to be good candidates to assemble coils for Superconducting Rotating Electric Machines (SuREMs). In this paper, to investigate influence of a Soft Magnetic Composite (SMC) material on the DC and AC HTS coil performances at cryogenic temperatures, GdBCO- and YBCO- based commercial tapes from different manufactures were used to assemble 10 HTS coils in doublepancake configuration. These tapes were wound using two different core structures, i.e. fixed and movable cores, having the same circular shape but different diameters as well as materials, i.e. fiberglass and $S M C$. Critical currents and AC transport current losses of these coils were measured using the electrical method. To evaluate the parallel and perpendicular components of the profile of magnetic flux density for each assembled HTS coil, a finite element model has been developed using Maxwell 2D. Eventually, the performance of different coils for SuREM application was discussed.
\end{abstract}

Index Terms - AC losses, Electric machine, Former/core material, HTS coils, REBCO tape

\section{INTRODUCTION}

$\mathrm{T}$ $\mathrm{HE}$ progress of second-generation (2G) superconducting materials and their high efficiency have accelerated the use of superconducting electric machines by replacing their conventional counterpart in higher power density applications such as electric aircraft [1]. The $2 \mathrm{G}$ high temperature superconducting (HTS) tapes, such as $\mathrm{ReBa}_{2} \mathrm{Cu}_{3} \mathrm{O}_{7-\mathrm{x}}$ ( $\mathrm{Re}$ is a rare earth material, usually $\mathrm{Y}, \mathrm{Gd}$, or $\mathrm{Sm}$ ) coated conductors

Manuscript received at 10 October 2020, revised at 17 and 30 November 2020 .

G. Messina and A. della Corte are with ENEA for EUROfusion, Via Enrico Fermi 45, 00044 Frascati, Roma, Italy. Corresponding author: G. Messina (email: giuseppe.messina.fra@enea.it, phone: +39 0694005674, fax: +39 694006119).

M. Yazdani-Asrami is with Department of Electronic and Electrical Engineering, University of Strathclyde, Glasgow, G1 1XW, U.K. He was a visitng researcher at the time at ENEA for EUROfusion, Via Enrico Fermi 45, 00044 Frascati, Roma, Italy (e-mail: mohammad.yazdaniasrami@strath.ac.uk).

F. Marignetti is with Department of Electrical Engineering and Information Technology, University of Cassino and Southern Lazio, Cassino, Italy. (email: marignetti@unicas.it)
(CC), possess several unique properties which make them quite attractive for being utilized in a wide range of large-scale power applications [1-4]. Adoption of HTS materials for power applications would be of great advantage due to their remarkable loss and efficiency performances as well as the fact that operating temperature can be set within the liquid nitrogen (LN2) temperature range. Therefore, designing and assembling a rotating electric machine with much higher torque density, efficiency, power density, and lighter weight would be possible by implementing HTS technology [5-8]. The development of these superconducting machines is also depends on the improvement of magnetic materials. To this end, a very promising magnetic material scenario involves the adoption of soft magnetic composite (SMC) materials. Due to their electrical and magnetic properties such as low hysteresis and eddy current losses, high permeability at low field strength, high saturation level, and uniform magnetic characteristics, SMCs are currently attracting the attention [910]. In particular, $S M C$ s can be used as magnetic core instead of conventional steel laminations, amorphous sheets or ferrites in electric machines applications [11-13]. For example, the properties of the coil former/core (shape, geometric dimensions, and type of material) and the substrate material of HTS tape (non-magnetic or ferromagnetic) dramatically affect on the performances of an axial flux electric machine when its double-pancake HTS coils are wound using a $2 \mathrm{G}$ tape around a trapezoidal or circular shaped $S M C$ core, and placed over the stator or rotor disc. Thus, to optimize electric machine design, investigation of SMC core behavior at cryogenic temperatures, as well as DC and AC characterizations of HTS coils are crucial [12-17].

In the literature, many papers have discussed the usage of HTS tapes and coils for different applications, although, there are not many papers comprehensively discussing the challenges of the winding process, material selection, fabrication process, and electrical testing of HTS coils as well as offering solutions for overcoming these technical and manufacturing issues. In [14-17], the design and assembling processes of an axial flux permanent magnet synchronous machine using HTS coils was investigated. For this purpose, trapezoidal and circular cores/formers were used to wind coils in double-pancake configuration, and their electrical properties and characteristics were measured, experimentally. In [18], 
AC loss of an HTS winding assembled by several doublepancake coils was measured. AC loss was reduced by placing a ferromagnetic disk near it. Basically, to decrease AC losses, magnetic field distribution around the winding was manipulated and reconfigured.

The Superconductivity Group at the Italian National Agency for New Technologies, Energy and Sustainable Economic Development (ENEA) located in the Frascati Research Center, Italy was investigating the role of ATOMET$E M 1$, an SMC material, on HTS coil performance for SuREM applications in collaboration with the Department of Electrical Engineering and Information Technology, University of Cassino and Southern Lazio, Italy. Two different materials, fiberglass (G10) and SMC (ATOMET-EM1), were used to fabricate cores/formers on which different HTS tapes were wound to produce ten circular double-pancake coils. We used a movable former to increase the core diameter. DC and AC perfiormances of coils were characterized in the self-field at LN2 temperature. In order to evaluate the components of magnetic flux density of each coil, a 2D finite element model was developed using the ANSYS Maxwell software package. This paper reports, discusses and compares experimental and simulation results.

\section{HTS COILS: CHALLENGES FOR SUPERCONDUCTING ROTATING ELECTRIC MACHINES APPLICATION}

There are challenges for the utilization of HTS coils in SuREMs, which are disscussed in the following sections:

\section{A. Coil manufacturing}

The selection of suitable tape to assemble an HTS coil is a challenge itself as the performances of the tapes produced by different manufactures are very different and are strongly influenced by magnitude and orientation of magnetic fields. Any change in $J_{\mathrm{c}}(\boldsymbol{B})$ characteristics of the tape leads to a huge change in the current-carrying capacity of the assembled coil as well as the electric loading and power density of the rotating machine fabricated by the coil. Critical current measurements in self-field and external magnetic field conditions are essential DC characterizations to help choosing a suitable tape for a specific application, knowing that following materials affect coil performances: 1) superconducting layer material ( $\mathrm{Gd}, \mathrm{Y}$, etc.); 2) substrate material (Hastelloy, NiW alloy, stainless steel, etc.) [19-20].

As the coil must be wound around a core as a former, its material and shape could increase or decrease the magnetic field components around the tape in the coil and thus, affect the DC and AC performances of the manufactured machine. On the other hand, the coil configuration also depends on the application, e.g. double-pancake, single-pancake, racetrack, or helical coils could be a suitable choice for a specific application or a disastrous choice for another one [21]. To overcome the coil manufacturing challenge, all these considerations must be taken into account as well as extra care and attention for handling very thin 2 G HTS tapes. This means any mistreatment (usually bending) of the thin HTS tape could reduce the critical current density of the tape and finally, the produced coil. This sort of mechanical damages usually leads to having weak points in a tape/coil which can initiate hotspots in the winding of the manufactured electric machine [22-23].

\section{B. Insulation and impregnation}

In a real rotating machine environment, all coils need turnto-turn insulation as well as a final stage impregnation process. The reason for this is for: 1) making each layer of tape in coil from another electrically isolated, 2) immobilizing the turns in the final manufactured coil [24] from any movement caused by assembling process, as well as electromagnetic force and vibrations during normal operation. 3) enabling the efficient heat transfer for the coils [25].

The type and thickness of insulation depend on many different factors such as the thickness of tape, voltage level of machine, number of turns, operating temperature, coolant type, and so on, so that choosing the best insulation material is not straightforward. The impregnation process is also an area to be investigated. A good impregnation material should have a high voltage withstanding capability, low thermal contraction/expansion, and high thermal conductivity at cryogenic temperatures [26-27], but there is not much information about the impregnation techniques and materials in the literature. While this process is an inevitable step for manufacturing a coil in electric machines, even though it has some drawbacks and can cause harm to the coil, too. The critical current degradation and $\mathrm{AC}$ loss increase are the results of choosing the wrong material for the impregnating process [27-28], which affect the performance of the superconducting electric machines, as their torque and power densities depend on their current-carrying capacity (electric loading), whereas their cooling efficiency depends on the AC loss as the main source of heat load in the machine coils/windings. On the other hand, the utilization of some insulation and impregnation materials at cryogenic temperatures, raises a huge concern about thermal cycling issues because there is not enough information about the characteristics of commercial insulation and impregnation materials at cryogenic temperatures; sure enough, after many times of thermal cycling or electric transients, the insulation could be weak or cracked [27, 29]. Thermal cycling studies are vital when the rotating machine is going to be used in critical applications such as electric aircraft [1] or energyrelated applications but, unfortunately, there is no comprehensive standard method for it at the moment. Frequent thermal cycling may cause delamination of the tape due to its contraction (including superconducting, stabilizer, and substrate layers), since the insulation and the former/core materials have different contraction/expansion coefficients. Thus, during the cooling down process, one layer would contract faster and more than other layers, and this imposes a huge transversal tension and stress as well as longitudinal tensile stress on different layers in the tape. This phenomenon together with the effect of moisture (in wet cryostats) accelerate the delamination process [30-31]. Note that the tackiness of the impregnation material makes the whole process more complicated. 


\section{Quench behavior}

The quench behavior of an HTS coil is related to the tape structure, heat transfer and thermal issues, joints, and transients in currents [32]. Weak and damaged points that can occur along the tape length during the coil assembling process trigger a partial quench or lead to a full coil quench. In addition, usually hotspots initiate in such weak points over time and could burn the insulation or cause some other electro-thermal stresses [33, 34]. These rapid electro-thermal transients lead to a quench due to low heat transfer in the internal turns which are unable to dissipate the amount of heat accumulated [2, 25]. Selection of an appropriate inter-turn insulation layer thus becomes critical. Kapton tape is typical adhesive insulation for turn-to-turn isolation, but it normally burns at medium range temperatures around 120 to $200 \mathrm{~K}$, (depends on the thickness) which makes it a weak thermal insulation, especially for wet-cryostat/winding machines. Since LN2 or other coolant liquids could penetrate underneath the Kapton, they produce a gas-sheath and decrease heat transfer especially during high current transients which leads to quench [25]. Suitable solid insulation made by epoxy resin and mixed with a filler powder such as alumina, aluminium nitride, or beryllium could be an solution [1, 25, 35]. Sometimes inside the coil, there are joints because of tape splicing which can be critical points for initiating a quench or during some transient happens in current such as a short circuit [2] or a short-term overload. One needs to consider this issue during coil design and fabricating stages to allow for sufficient cooling of the coil.

\section{AC loss characteristics}

Accurate estimation of the AC loss of a coil and, as a result, its efficiency is very important for electric machine applications [36-37]. This AC loss causes extra heating and temperature rise if the cooling system does not work efficiently to dissipate it from the cryostat. The problem starts when the AC loss is estimated for a pure sinusoidal current or external magnetic field, and the cooling system is designed accordingly. Some harmonics in the magnetic field due to the distribution of windings or failure of the bearings can occur under normal operating condition of an electric machine [38]. On the hand, current can be nonsinusoidal too because of the harmonics produced by power electronic converters [21, 32]. AC loss could drastically increase when this happens [21, 32] and as a consequence, the heat load of the machine increases. Therefore, it must be taken into account when estimating AC loss [39] and designing the most suitable cooling system, otherwise, it would either lead to thermal breakdown of the cooling system or temperature rise of the machine winding. Having high precision in AC loss calculation/estimation method together with meaningful experimental results would be a great help for manufacturing suitable HTS coils for the rotating electric machine to avoid such thermal runaway.

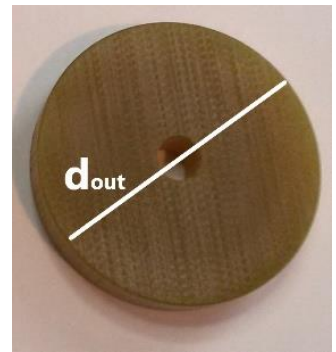

(a)

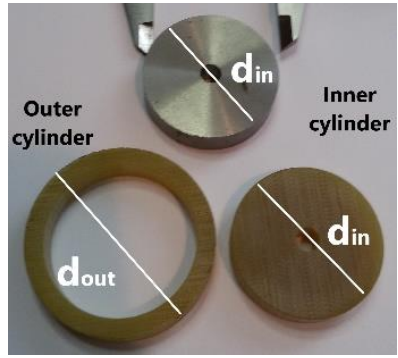

(b)
Fig. 1. Core configurations a) Fixed, b) Movable

TABLE I

GEOMETRIC SPECIFICATION OF TWO TYPES OF CORE CONFIGURATIONS

\begin{tabular}{ccc}
\hline \hline Type of core & Fixed & Movable \\
\hline Outer diameter & $40 \mathrm{~mm}$ & $50 \mathrm{~mm}$ \\
Inner diameter & & $40 \mathrm{~mm}$ \\
Height & $10 \mathrm{~mm}$ & $10 \mathrm{~mm}$ \\
\hline \hline
\end{tabular}

\section{HTS COIL CONFIGURATIONS AND ASSEMBLY}

\section{A. Tape materials and core configurations}

Two types of circular core configurations, fixed and movable, were manufactured in the ENEA laboratory, as shown in Fig.1(a) and Fig.1(b), respectively.

The movable core configuration, in particular, consists of two concentric cylinders: an outer one, on which the HTS tape is wound, and an inner one easily replaceable, as shown in Fig.1(b). Different materials, $G 10$ and $S M C$, were used for both the fixed core and the inner cylinder of the movable core. Note that the outer cylinder, concentric to the inner one, is made with G10. The geometric parameters of the two types of core configurations are shown in Table I.

Several meters of REBCO CC tapes, commercially available and produced by different manufacturers, were used to wind double-pancake HTS coils around different circular core configurations. The specifications of these tapes are as follows:

1. YBCO tape, SCS4050 with cross-section $4.0 \mathrm{~mm} \times 0.1$ $\mathrm{mm}$ and a Hastelloy substrate, manufactured by SuperPower (SP) Inc: nominal critical current $I_{c}=100 \mathrm{~A}$ at $77 \mathrm{~K}$ and self-field;

2. YBCO Amperium ${ }^{\circledR}$ copper-laminated tape with crosssection $4.8 \mathrm{~mm} \times 0.2 \mathrm{~mm}$ and a ferromagnetic substrate, manufactured by AMSC $(\mathrm{Am})$ : nominal critical current $I_{c}$ $>100 \mathrm{~A}$ at $77 \mathrm{~K}$ and self-field;

3. GdBCO tape, HCN04150 with cross-section $4 \mathrm{~mm} \mathrm{x}$ $0.105 \mathrm{~mm}$ and a Hastelloy substrate, manufactured by SuNAM Co. Ltd (Su): nominal critical current $I_{c}=220 \mathrm{~A}$ at $77 \mathrm{~K}$ and self-field.

\section{B. Manufacturing and assembling processes of the coils}

Before starting the coil winding process, a $25 \mu \mathrm{m}$ thick Kapton adhesive tape was placed on the REBCO side of $18 \mathrm{~m}$ of $S P$ tape, $7 \mathrm{~m}$ of $A m$ tape and $18 \mathrm{~m}$ of $S u$ tape, respectively. This insulating tape also fixes the distance between the turns. 


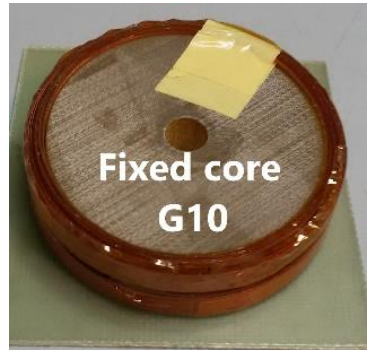

(a)

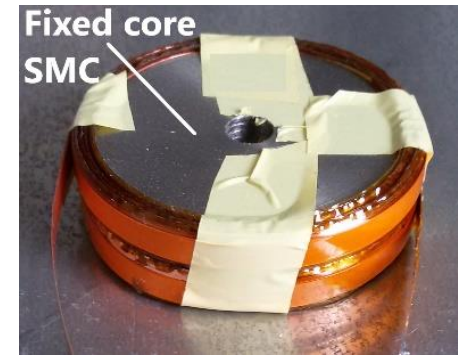

(b)
Fig. 2. HTS coils wound on a fixed core with: a) $G 10$ core material using $S u$ tape. b) $S M C$ core material using $S P$ tape

TABLE II

SPECIFICATIONS OF THE TEN MANUFACTURED DOUBLE-PANCAKE COILS

\begin{tabular}{ccccccc}
\hline \hline $\begin{array}{c}\text { HTS } \\
\text { tape }\end{array}$ & $\begin{array}{c}\text { Core } \\
\text { Config. }\end{array}$ & $\begin{array}{c}\text { Dext } \\
(\mathrm{mm})\end{array}$ & $\begin{array}{c}\text { Core } \\
\text { Material }\end{array}$ & Turns & $\begin{array}{c}\text { Total } \\
\text { tape } \\
\text { length }\end{array}$ & Coil Code \\
\hline \multirow{3}{*}{$\mathrm{Su}$} & \multirow{2}{*}{ Fixed } & 45 & G10 & 34 & $4.5 \mathrm{~m}$ & Su_FG_34 \\
\cline { 2 - 7 } & \multirow{2}{*}{ Movable } & 55,16 & G10 & 26 & $4.5 \mathrm{~m}$ & Su_MG_26 \\
& 55,16 & SMC & 26 & $4.5 \mathrm{~m}$ & Su_MS_26 \\
\hline \multirow{3}{*}{ SP } & \multirow{2}{*}{ Fixed } & 44,8 & G10 & 34 & $4.5 \mathrm{~m}$ & SP_FG_34 \\
\cline { 2 - 7 } & \multirow{2}{*}{ Movable } & 54,8 & SMC & 34 & $4.5 \mathrm{~m}$ & SP_FS_34 \\
\cline { 3 - 7 } & \multirow{2}{*}{ Am } & 55 & G10 & 26 & $4.5 \mathrm{~m}$ & SP_MG_26 \\
& \multirow{2}{*}{ Fixed } & 46,5 & G10 & 26 & $4.5 \mathrm{~m}$ & SP_MS_26 \\
\hline \hline
\end{tabular}

The benefits in terms of no degradation of the critical current of the tape when it is subjected to compression stresses are known. However, it was interesting to compare the critical currents of coils wound by tapes with different mechanical properties, and the possible effects caused by tension stresses. So, with the REBCO side oriented outwards, the insulated CC tapes were wound on a fixed and movable circular cores by a commercial winding machine under a proper tension. All the coils were wound in a double-pancake configuration and their winding process started at mid-section of the tape, so that the two sections (pancakes) of a coil are separated by a small gap. As can be seen in Table II, ten double-pancake coils, with the same circular shape but different turns number, were assembled: 6 coils with the fixed core configuration using different core materials, G10 (3 coils) and SMC (3 coils) as shown in Figs. 2(a) and 2(b), respectively; 4 coils with the movable core configuration using different core materials, G10 (2 coils) and SMC (2 coils) for the internal cylinder as shown in Figs. 3(a) and 3(b), respectively.

To distinguish one coil from another, each coil is identified by a three-point code indicator, respectively: HTS tape manufacturer (Su, SP, Am); core configuration (F, M) and material $(\mathrm{G}, \mathrm{S})$; turns number $(26,34)$. After the winding process, to suppress mechanical vibration, all coils were fixed by cryogenic tape symmetrically distributed over the perimeter of the coil.

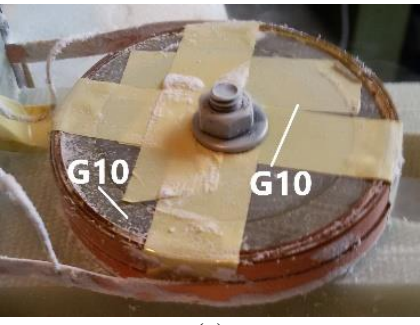

(a)

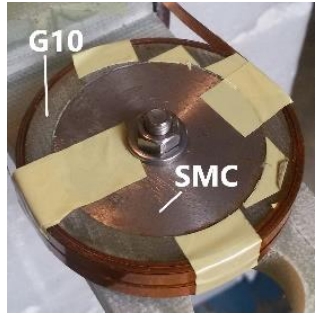

(b)
Fig. 3. HTS coils wound on a movable core with: a) $G 10$ core material using $S u$ tape. b) $S M C$ core material using $S P$ tape

TABLE III

CRITICAL CURRENT OF THE MANUFACTURED HTS COILS @ 77 K

\begin{tabular}{cc}
\hline \hline Coil Code & Ic_coil @ 77 K \\
\hline Su_FG_34 & $88 \mathrm{~A}$ \\
Su_FS_34 & $75 \mathrm{~A}$ \\
Su_MG_26 & $89 \mathrm{~A}$ \\
Su_MS_26 & $88 \mathrm{~A}$ \\
SP_FG_34 & $55 \mathrm{~A}$ \\
SP_FS_34 & $47 \mathrm{~A}$ \\
SP_MG_26 & $61 \mathrm{~A}$ \\
SP_MS_26 & $59 \mathrm{~A}$ \\
Am_FG_26 & $79 \mathrm{~A}$ \\
Am_FS_26 & $69 \mathrm{~A}$ \\
\hline
\end{tabular}

\section{EXPERIMENTAL SETUP AND MEASUREMENTS}

\section{A. DC characterization of the manufactured coils}

To determine the critical current of each coil, currentvoltage (I-V) curves were measured using the standard fourprobe electrical method. All DC measurements were conducted in a LN2 bath $(77 \mathrm{~K})$ and self-field condition. As a first step, the I-V curve of HTS coils wound on different core configurations and core materials using HTS tape with no magnetic substrate $(S u$ and $S P$ ) were measured. As a second step, the I-V curve of HTS coils, 26 turns, wound on different core configurations using $A m$ tape with magnetic substrate were measured. As a criterion for the critical current $\left(\mathrm{I}_{c}\right)$ determination, $1 \mu \mathrm{Vcm}^{-1}$ has been chosen; so, by measuring the voltage across the whole tape length, the $I_{c}$ values versus turn number of each coil were obtained and listed in Table III.

\section{B. AC characterization of the manufactured coils}

An HTS coil carries out electrical current without energy dissipation in DC condition but in AC condition it shows an impedance, $Z_{\text {coil }}=R_{\text {coil }}+j \omega L_{\text {coil }}$ : the imaginary part comes from the coil inductance while the real part is produced by $\mathrm{AC}$ losses [16]. In this section, the AC characteristics of HTS coils were investigated, including measurement of $\mathrm{AC}$ transport current losses and the coil impedance, $\mathrm{Z}_{\text {coil }}$.

\section{B.1. Transport AC loss measurements}

The experimental setup for transport AC loss measurements is shown in Fig. 4. The HTS coil under test, connected in series to a $40 \mathrm{~m} \Omega$ shunt resistance, was immersed in a nonmetallic cryostat containing a LN2 bath and supplied by an AC current source which could produce maximum $100 \mathrm{~A}$, peak to peak, with a frequency between 0 to $400 \mathrm{~Hz}$. 


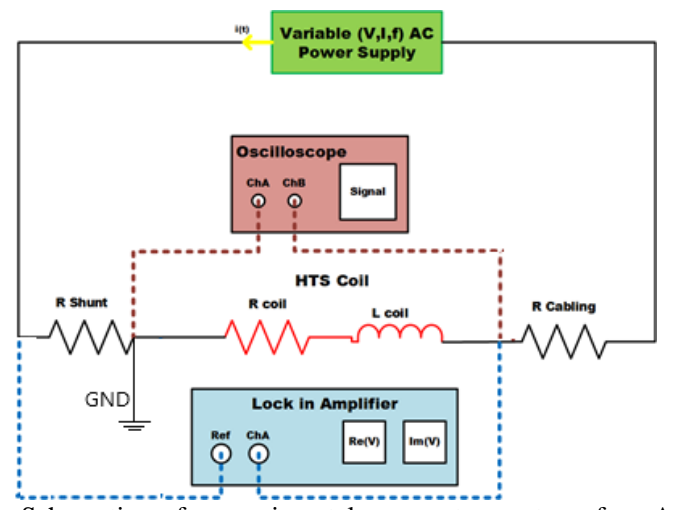

Fig. 4. Schematic of experimental apparatus setup for AC loss measurements

TABLE IV

MEASURED AND CALCULATED INDUCTANCES OF HTS COILS AT 77 AND $300 \mathrm{~K}$

\begin{tabular}{cccc}
\hline \hline Coil code & \multicolumn{2}{c}{ Lcoil coil @ 77K $(\boldsymbol{\mu H})$} & $\begin{array}{c}\text { Lcoil coil @ } \\
\mathbf{3 0 0 K}(\boldsymbol{\mu H})\end{array}$ \\
\hline & $\begin{array}{c}\text { Measured by } \\
\text { LCR meter }\end{array}$ & $\begin{array}{c}\text { Calculated from } \\
\text { AC losses } \\
\text { measurements }\end{array}$ & $\begin{array}{c}\text { Measured by } \\
\text { LCR meter }\end{array}$ \\
\cline { 2 - 4 } Su_FG_34 & 71 & 61 & 77.5 \\
Su_FS_34 & 98 & 104 & 106 \\
Su_MG_26 & 55 & 55 & 57 \\
Su_MS_26 & 67 & 69 & 71 \\
SP_FG_34 & 65 & 68 & 69 \\
SP_FS_34 & 95 & 115 & 110 \\
SP_MG_26 & 57 & 60 & 60 \\
SP_MS_26 & 69 & 73 & 73 \\
Am_FG_26 & 44.5 & 45 & 46.5 \\
Am_FS_26 & 62 & 68 & 70 \\
\hline \hline
\end{tabular}

A digital oscilloscope was used to observe the signals and check the reference voltage waveform and its amplitude during the tests. The voltage signal, $\mathrm{V}_{\text {coil }}$, across the HTS coil impedance, $Z_{\text {coil }}(f)$, contains an undesireable imaginary component coming from the coil inductance $\left(L_{\text {coil }}\right)$ and a real component $\left(\mathrm{R}_{\text {coil }}\right)$ which, being produced from $\mathrm{AC}$ losses, is the measure of our interest. To measure and separate the $V_{\text {coil }}$ components, a dual-channel lock-in amplifier was used. There are some difficulties related with the lock-in measurements. First of all, a correct measurement of the phase difference that decides the losses is very important to give an accurate result; the large inductance produces a large difference between inphase and quadrature components of voltage (several orders of magnitude), which may lead to troubles with the dynamic reserve of the used Lock-in amplifier input stage. This occurs when the geometric parameters of the coil and its turns number are large that the inductance, $\mathrm{L}_{\text {coil }}$, assumes values of the order of $\mathrm{mH}$ : this drawback can be overcome by using a compensating coil $[40,16]$.

In this paper, we are dealing with coils of small dimensions and few turns $\left(\mathrm{L}_{\text {coil }}\right.$ are tens of $\left.\mu \mathrm{H}\right)$, so the use of a large dynamic reserve in the lock-in amplifier has shown to introduce a small noise in the phase without adopting a reactive voltage compensation and it was also possible to obtain a high value of the SNR (Signal-Noise Ratio) in a wide range of frequency. Furthermore, all the measures were carried out taking care not to introduce stray inductances into the circuit and to avoid magnetic couplings with the environment.

All the voltage signals, acquired by a lock-in amplifier, were referred to the ground point chosen on the HTS coil under test. As a first step, AC transport current loss $\left(P_{\text {loss }}\right)$ versus RMS current at different frequencies (from $2 \mathrm{~Hz}$ up to $100 \mathrm{~Hz}$ ) was measured for each HTS coil. As the topic of this paper concerns the electric machine application, the $60 \mathrm{~Hz}$ AC loss experimental data of HTS coils with the same turn numbers, 34 or 26 turns, but different tapes and different core materials and configurations, were shown as typical results in Fig.5 and Fig.6, respectively.

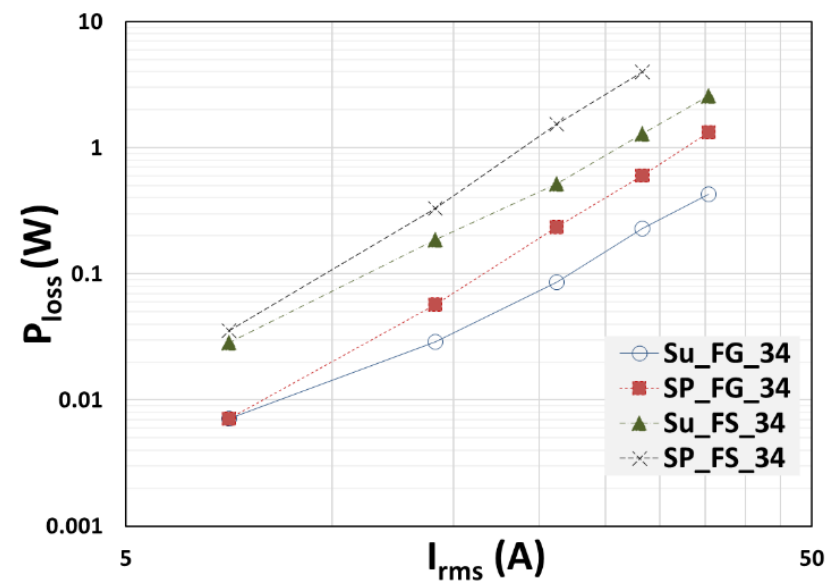

Fig. 5. AC losses $\left(\mathrm{P}_{\text {loss }}\right)$ versus RMS current at $60 \mathrm{~Hz}$ for HTS coils having 34 turns of different tape $(S u$ and $S P$ ) and fixed core configuration but different core material ( $G 10$ and $S M C)$

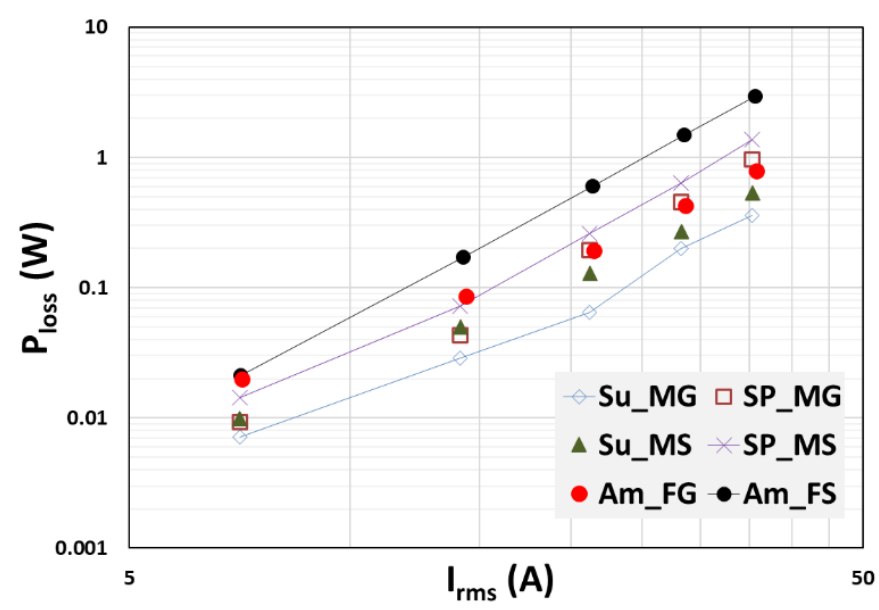

Fig. 6. AC losses $\left(\mathrm{P}_{\text {loss }}\right)$ versus RMS current at $60 \mathrm{~Hz}$ for HTS coils having 26 turns of different tapes $(\mathrm{Su}, \mathrm{SP}$ and $\mathrm{Am})$, core configuration and core material.

\section{B.2. Components of coil impedance}

A preliminary measurement of the coil inductance value, $\mathrm{L}_{\text {coil }}$, of each HTS coils at LN2 $(77 \mathrm{~K})$ and room $(300 \mathrm{~K})$ temperatures was done using a high precision LCR meter.

These experimental results at $77 \mathrm{~K}$, reported in Table IV, are in agreement with the results derived from the imaginary voltage component $\mathrm{V}_{\text {coil }}$ acquired during the $\mathrm{AC}$ loss measurements: $L_{\text {coil }}=\frac{\operatorname{Im}\left(V_{\text {coil }}\right)}{2 \cdot \pi \cdot f \cdot I o p}$. 
The amount of heat associated with the AC loss in the tape, used to wind the coil, is the active power supplied to the coil by AC current source. This power is modeled as the power dissipated on the $\mathrm{R}_{\text {coil }}$ resistance by the joule effect. Therefore, the real component of the coil impedance, derived from the RMS current in-phase component voltage $\mathrm{V}_{\text {coil }}$, is very useful to identify the AC behavior of the coil: $R_{\text {coil }}=\frac{\operatorname{Re}\left(V_{\text {coil }}\right)}{I_{o p}}$

The $\mathrm{R}_{\text {coil }}$ curve (per unit length) versus frequency of each HTS coil wound using $\mathrm{Su}, \mathrm{SP}$ or $\mathrm{Am}$ tapes is shown in Fig.7 when the applied RMS current was $35 \mathrm{~A}$.

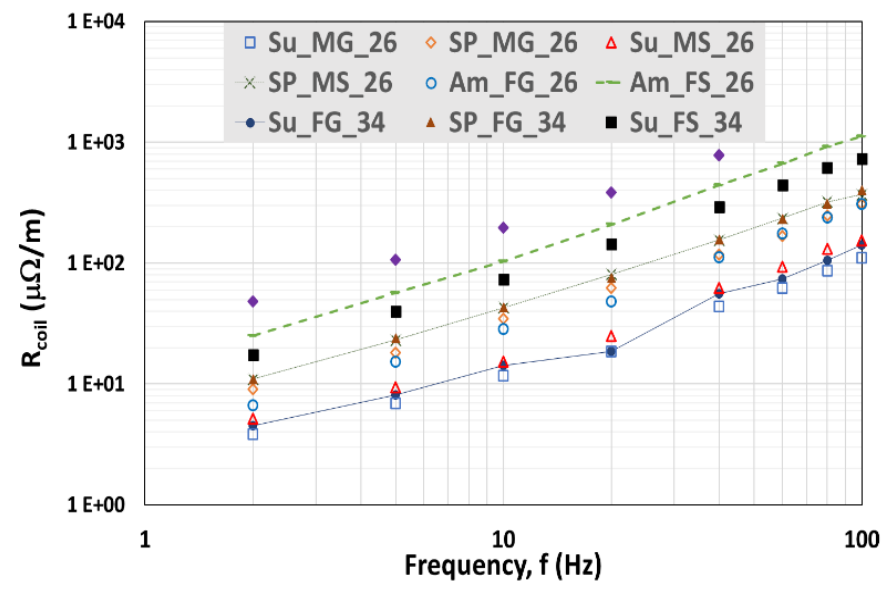

Fig. 7. $R_{\text {loss }}$ per meter versus RMS frequency at $35 \mathrm{~A}_{\text {rms }}$ curves of HTS wound using different tape, core material and core configuration

\section{Magnetic characterization of SMC material}

An SMC specimen was machined to obtain the sample shown in Fig. 8(a), on which two copper windings with different turns numbers were wound. With reference to the Fig. 8(b), when a sinusoidal current, flowing into the primary winding and supplied by a current source, generates a magnetic field, an induced voltage proportional to magnetic flux density (B) across the secondary winding can be measured. A $B-H$ magnetization curve was obtained at $300 \mathrm{~K}$ and $50 \mathrm{~Hz}$ frequency and then loaded into the material library of ANSYS Maxwell software to model the magnetic behavior of the $S M C$ material. This curve was shown in Fig. 9. Because the B-H curve of the SMC material does not change in the temperature range between $77 \mathrm{~K}$ and $300 \mathrm{~K}$ [10], it was possible to extrapolate the SMC core relative magnetic permeability, $\mu_{\mathrm{r}}$, from the curve of Fig. 9, and then use it in the simulation studies of section $\mathrm{V}$.

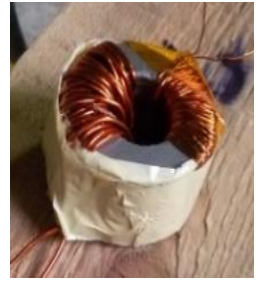

(a)

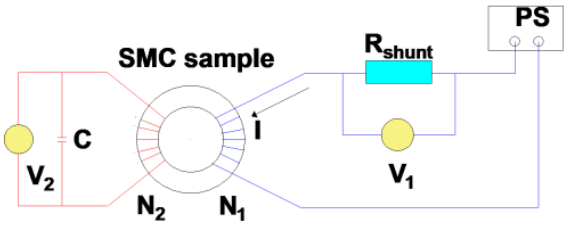

(b)
Fig. 8. Magnetic characterization of $S M C$ material. a) $S M C$ sample under test. b) Experimental set-up for $S M C$ magnetization curve measurement

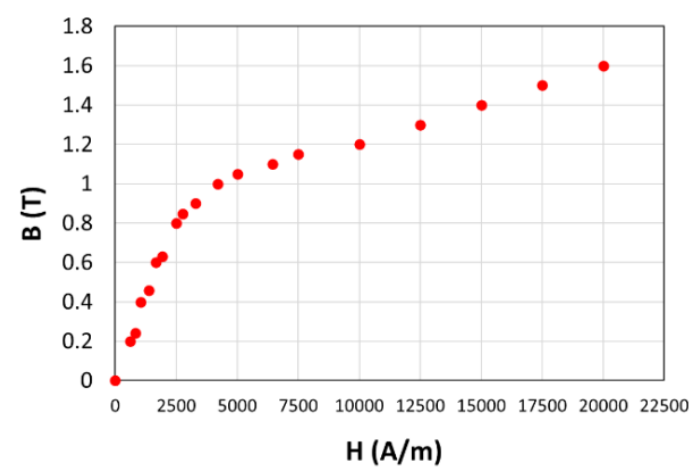

Fig. 9. SMC magnetization curve at $50 \mathrm{~Hz}$ and $300 \mathrm{~K}$ similar to that of $77 \mathrm{~K}$

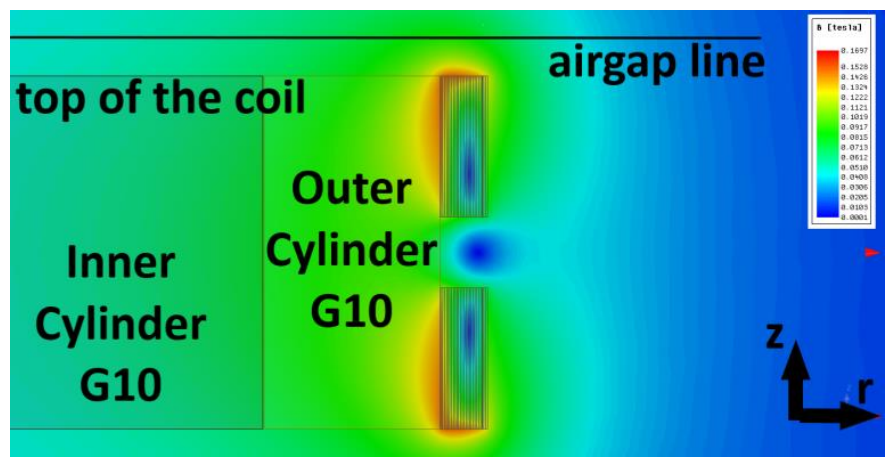

Fig. 10. Magnetic flux density for $S u \_M G \_26$ coil at $I_{o p}=70 A$

\section{SIMULATION STUDY}

The profile of the components of the air-gap magnetic flux density, can be a useful tool for the design of an axial flux electrical machine, for example, with HTS coils placed on the stator or rotor discs. In particular, the radial component, $\mathrm{B}_{\text {radial }}$, is useful to estimate the $\mathrm{AC}$ losses of a coil whereas the axial component, $\mathrm{B}_{\mathrm{axia}}$, is useful to calculate the profile and the strength of the torque when HTS coils are placed on rotor disc or to design the PMs axial thickness for HTS coils placed on stator disc [15]. To investigate the influence of the former/core (material and configuration) and the tape parameters on the magnetic field profile of each coil, a magnetostatic simulation study was carried out using a 2D finite element model in the ANSYS Maxwell software package.

The cross-section of each coil, modelled in the r-z plane, consists of several domains: the surrounding air, the core and the turns. Each turn includes the superconducting layer, the substrate and the stabilization matrix. The gap along zdirection between two single pancakes of each HTS coil is 2 $\mathrm{mm}$. Fig. 10 shows the distribution of the magnetic flux density profile for the $S u$ coil with 26 turns carrying an operating transport current, $I_{o p}=70 \mathrm{~A}$ and wound on a movable core with $G 10$ core material.

Assuming that each coil carries an operating transport current $I_{o p}=0.8 \cdot I_{c}$ (see table $\mathrm{V}$ ), the axial and the radial component profiles of the magnetic flux density for each coil were estimated along the airgap line and on top of the coil, respectively. Both components of the B profiles shown as a function of the distance from its magnetic axis, as following: 
- Fig.11 shows the comparison of $B_{\text {axial }}$ profiles along the airgap line (1 mm from top of the coil) for coils with the same turns number (26) and configuration (Movable) but different HTS tape and core materials;

- Fig.12 shows the comparison of $B_{\text {radial }}$ profiles for coils with the same turns number (26) and core configuration (Movable) but different HTS tape and core materials;

- Fig.13 shows the comparison of $\mathrm{B}_{\text {axial }}$ profiles along the airgap line (1mm from the top of the coil) for coils with the same core configuration (Fixed) but different tape, turns number and core materials;

- Fig.14 shows the comparison of $\mathrm{B}_{\text {radial }}$ profiles for coils with the same core configuration (Fixed) but different HTS tape, turns number and core materials.

TABLE V

SPECIFICATION OF DIFFERENT HTS COILS FOR THE SIMULATION STUDY

\begin{tabular}{ccc}
\hline \hline Coil & Ic & Iop \\
\hline Su_FG_34 & 88 A & $60 \mathrm{~A}$ \\
Su_FS_34 & $75 \mathrm{~A}$ & \\
Su_MG_26 & $89 \mathrm{~A}$ & $70 \mathrm{~A}$ \\
Su_MS_26 & 88 A & \\
SP_FG_34 & 55 A & \multirow{2}{*}{$38 \mathrm{~A}$} \\
SP_FS_34 & 47 A & \\
SP_MG_26 & $61 \mathrm{~A}$ & \multirow{2}{*}{$47 \mathrm{~A}$} \\
SP_MS_26 & 59 A & \\
Am_FG_26 & 79 A & 55 A \\
Am_FS_26 & 69 A & \\
\hline \hline
\end{tabular}

From Fig. 15, it can be seen that the profile of the $B_{\text {radial }}$ component, perpendicular to the HTS tape of the $S u \_M G \_26$ coil, has the maximum local value at the top edge of the central turns (6-7-8).

By varying the coil operating current from 0 to $180 \mathrm{~A}$, the load line was obtained from a simulation study, reported on the $I_{\text {coil }}-B_{\text {radial,max }}$ and shown in Fig. 16. The intersection of this load line with the $I_{c}-B_{\text {perpendicular }}$ curves obtained from $I_{c}$ measurements on the bare $S u$ tape at different external magnetic fields and temperatures gives the value of $I_{c}$ for the coils made by $S u$ tape at different temperatures.

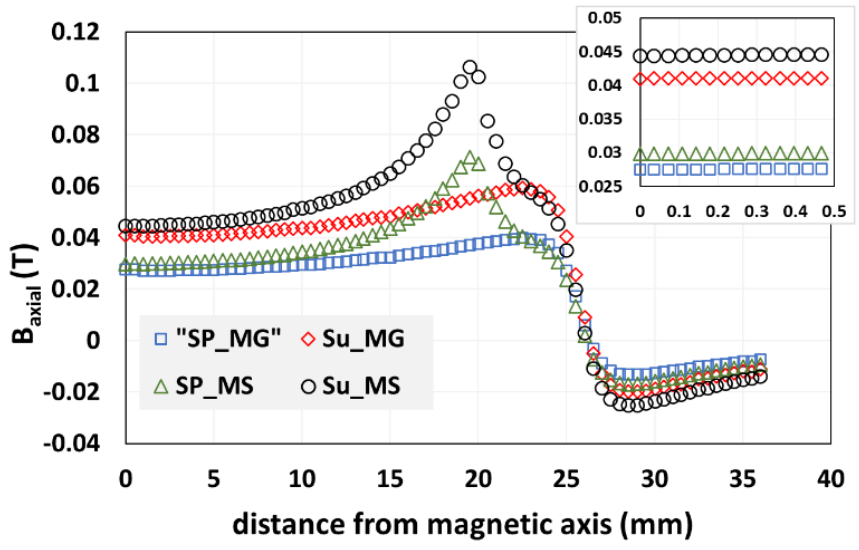

Fig. 11. $\mathrm{B}_{\text {axial }}$ versus distance from the magnetic axis on the airgap line for coils with the same turns number (26) and core configuration but different tape and core materials

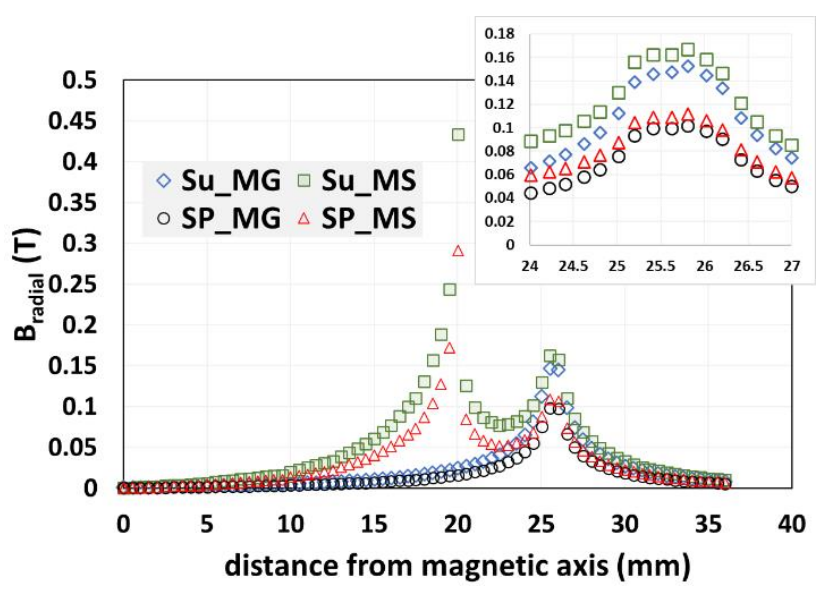

Fig. 12. $B_{\text {radial }}$ versus distance from the magnetic axis for coils with the same turns number (26) and core configuration (Movable) but different tape and core materials

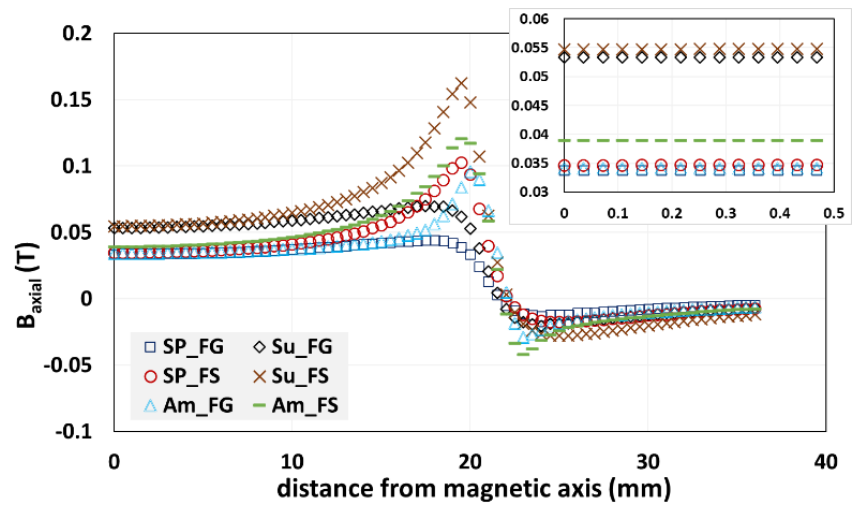

Fig. 13. $B_{\text {axial }}$ versus distance from the magnetic axis on the airgap line for coils with the same core configuration (Fixed) but different tape, turns number and core materials

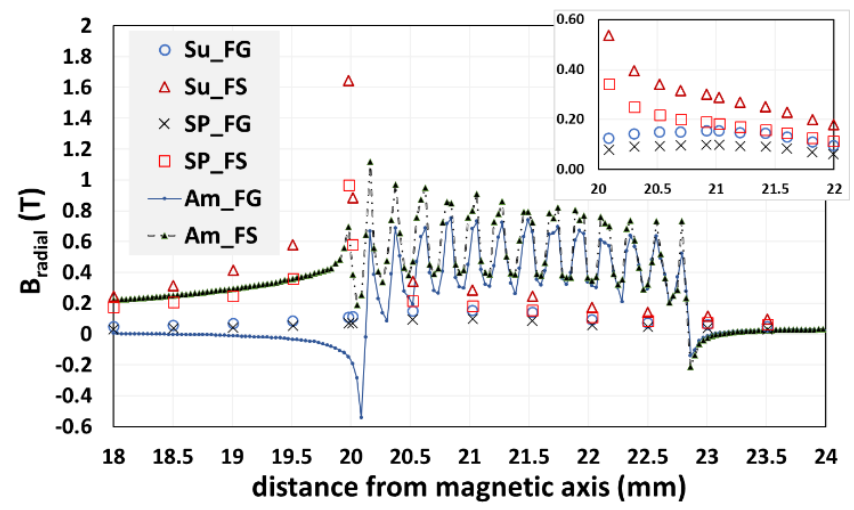

Fig. 14. $B_{\text {radial }}$ versus distance from the magnetic axis for coils with the same core configuration (Fixed) but different tape, turns number and core materials

\section{DiscuSsions}

The discussion on findings and comparison of the experimental and modelling results of the ten manufactured HTS coils were done according to their potential arrangement inside a superconducting rotating electric machine in this context, the choice of using one of the aforementioned coils depends whether the coil is located on the field winding or on 
the armature winding.

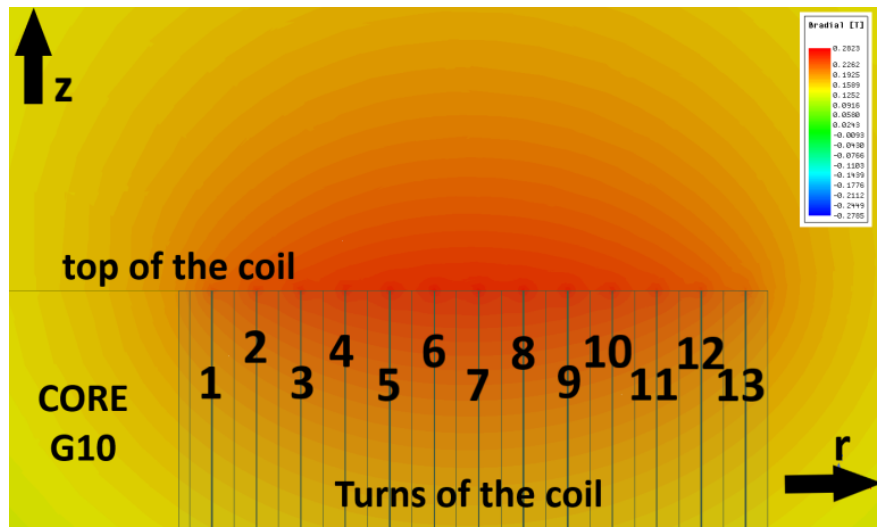

Fig. 15. $\mathrm{B}_{\text {radial }}$ for $S u$ coil in the movable core configuration with the $G 10$ core material, at $\mathrm{I}_{\mathrm{op}}=120 \mathrm{~A}$

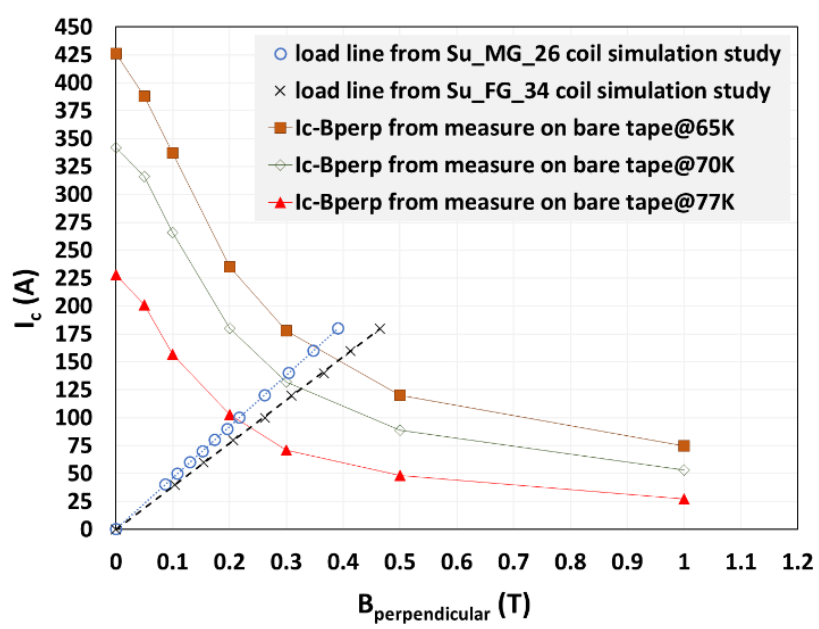

Fig. 16. Load line for $S u_{-}$coils in the movable core configuration

For example, HTS coils positioned on the stator disc of an axial flux permanent magnets synchronous machine, could be compared in terms of minimum AC loss and maximum current density since they are mostly related to electric loading of machine. On the contrary, the HTS coils on the field winding of this machine with a conventional armature winding, could be compared in terms of the maximum magnetic flux density as well as quality of produced magnetic field waveform (as sinusoidal as possible). Note that the field winding controls the magnetic loading of the machine. Therefore, the choice of the best coil to use will be the right trade-off between several parameters depending on their application.

\section{A. DC characterization}

As can be seen in Table III, the coils wound by Gd-based tape with the same length of tape, have the highest $I_{c}$ in selffield. Instead, in comparison to the coils wound using Y-based tape in fixed core configuration and with almost the same outer diameter, coils with $A m$ tape have a higher $\mathrm{I}_{\mathrm{c}}$ value despite the lowest turns number. Even the core material has a significant role on the coil $I_{c}$ value in both core configurations. The $I_{c}$ value of HTS coils in fixed core configuration with the G10 core material is higher than with the SMC core. This experimental result is in agreement with the magnetostatic simulation result.

As shown in Figs. 12 and 14, the SMC material modifies the magnetic field profile and increases the value of the radial component of the magnetic flux density, perpendicular to the tape, reducing $I_{c}$. For the same amount of tape used in the fixed core configuration, increasing the internal diameter and decreasing the turns number of coils with a movable core configuration, a better performance for the $S M C$ material in terms of the magnetic flux density profile was obtained. It should be noted also that the mechanical stability of the $\mathrm{Am}$ tape, with a silver stabilization matrix and a magnetic substrate, is better than the $S u$ and $S P$ tapes with a copper matrix stabilization and non-magnetic substrate instead. So, $A m$ and $S u$ tapes are the best options to assemble HTS coils with a higher number of turns and high current carrying performance, respectively.

\section{B. AC characterization}

Studying the behavior of each coil in AC condition is crucial for the design of the static (power transformers) or rotating electric machines. By comparing the obtained AC loss results, it is possible to estimate the real component of the coil impedance and choose the most suitable coil (tape, core material, core configuration, and so on) to increase the efficiency of the electric machine.

As shown in Fig. 5, for the same turns number, core configuration and core material, the $\mathrm{AC}$ transport current losses of $S u$ coils measured at $60 \mathrm{~Hz}$ and $35 \mathrm{~A}_{\mathrm{rms}}$, are lower than those of $S P$ coils due to the tape properties. This means that, at the same RMS transport current, the associated Lorentz force must overcome a lower pinning force into the tape with a lower critical current. The reason is, the coil with the tape which has an area more penetrated by the magnetic flux, has a greater hysteresis loss than the one with the same turns number and geometric parameters, but a different tape with a higher $\mathrm{I}_{\mathrm{c}}$.

As expected, at the same tape and transport current, the increase of the magnetic field components due to the magnetic core material is such as to produce an increase of losses. AC losses of $S u$ and $S P$ coils with $S M C$ core material are 6 and 8 times higher than $G 10$ core material counterparts, respectively.

Obviously, increasing the coil diameter while changing from a fixed to a movable configuration and keeping the length of $S u$ and $S P$ tapes used to wind the coils with 26 turns, decreases the AC loss difference between the coils with $S M C$ and $G 10$ core materials $\left(\triangle \mathrm{P}_{\mathrm{SMC}-\mathrm{G} 10}\right)$ at the same frequency and current value (see Fig. 6), i.e., $\Delta \mathrm{P}_{\text {SMC-G10 }}$ of $S u \_F i x e d \_34$ coils is almost $2 \mathrm{~W}$ whereas $\Delta \mathrm{P}_{\text {SMC-G10 }}$ of $S u_{-}$Movable_26 coils is almost $0.15 \mathrm{~W}$ at $35 \mathrm{~A}_{\mathrm{rms}}$ and $60 \mathrm{~Hz}$. Due to the magnetic substrate, coils with 26 turns and wound by $A m$ tape on the fixed core using different materials, have higher AC losses than $S u$ or $S P$ coils counterpart.

Considering instead the $\mathrm{I}_{\mathrm{op}} / \mathrm{I}_{\mathrm{c}}=0.4$ parameter, at the same turns number (34), configuration (Fixed) and core material, $S P$ coils show slightly lower losses than $S u$ coils: $S P_{-} F G=0.25$ $\mathrm{W}$ and $S P \_F S=1.2 \mathrm{~W} ; S u_{-} F G=0.4 \mathrm{~W}$ and $S u_{-} F S=1.5 \mathrm{~W}$ 
(see Fig. 5). The results are identical for coils with 26 turns and a movable core configuration: $S P_{-} M G=0.25 \mathrm{~W}$ and $S P \_M S=0.3 \mathrm{~W} ; S u_{-} M G=0.35 \mathrm{~W}$ and $S u \_M S=0.5 \mathrm{~W}$ (see Fig. 6). This highlights as the choice of a $S M C$ core further increases the AC losses when the turns number of coils made with the same tape and the same configuration (Fixed or Movable) increases.

Due to an SMC core the AC losses increasing is also confirmed in the coil wound with AMSC tape: $A m_{-} F G=0.5$ $W$ and $A m \_F S=1.5 \mathrm{~W}$.

The comparison of the real component of the coil impedance, $R_{\text {coil }}$, per cycle and unit length of different tapes is shown in the Fig. 7. The $\mathrm{R}_{\text {coil }}$ trend shows the SMC core material is the best choice for coils wound on movable core configuration using non-magnetic substrate tape. $\mathrm{R}_{\text {coil }}$ grows linearly with frequency as it takes into account the power dissipation but its value is always lower than the reactive part $\mathrm{X}_{\text {coil }}=2 \pi \mathrm{f} \cdot \mathrm{L}_{\text {coil }}$ so that taking into account an axial flux permanent magnet synchronous machine with HTS coils on the stator disc, the imaginary component of the synchronous impedance $Z_{\mathrm{s}}$ should be higher than the real component. This means that the stator ampere-turns, opposing the rotor ampereturns, could demagnetize the permanent magnets and decrease the total magnetization level of the machine when tested under the short-circuit condition.

\section{Simulation study}

Supposing the fixed core configuration coil is arranged on the rotor disc of an axial flux permanent magnet synchronous machine and referring to the results in Fig. 13, due to the higher ampere-turns number $S u_{-} F S$ and $S u_{-} F G$ coils have the highest $\mathrm{B}_{\text {axial }}$ value ( $55 \mathrm{mT}$ and $53 \mathrm{mT}$, respectively), estimated on the coil magnetic axis and the airgap line $(1 \mathrm{~mm}$ from the top of the coil), than the $S P$ and Am counterparts. However, the $S M C$ core material significantly changes the $\mathrm{B}_{\text {axial }}$ profile causing a strong field gradient $\left(\Delta B_{S M C}=107 m T>\Delta B_{G 10}=17\right.$ $m T$ ) when moving from the coil axis to the first turn, and as a consequence, the waveform of the field winding is strongly distorted. As the core diameter increases from the fixed to the movable core configuration, the $S u$ coils always have the highest $\mathrm{B}_{\text {axial }}$ values compared to the $S P$ counterpart but this discrepancy decreases: $\Delta B_{S u-S P}=21 \mathrm{mT}$ and $\Delta B_{S u-S P}=14 \mathrm{mT}$ for the fixed and movable core configurations, respectively (see Fig. 11). From Fig. 12, the difference between $B_{\text {radial }}$ values estimated in correspondence with the central turns on top of the $S u$ and $S P$ coils is almost $\Delta B_{S u-S P}=50 \mathrm{mT}$ for both core materials in the movable core configuration. This causes a critical current reduction of $59 \%$ for the $S u$ coils versus a reduction of $40 \%$ in the $S P$ coils, compared to the $\mathrm{I}_{c}$ of the bare tape. Fig. 14 shows that for coils with a fixed core configuration, the difference $\Delta B_{S u-S P}$ is $56 \mathrm{mT}$ (on central turns) and $68 \mathrm{mT}$ (on the first turn) for the $G 10$ and $S M C$ core materials, respectively. This discrepancy between the $\mathrm{B}_{\text {radial }}$ values is even more pronounced for the $A m$ coils wound by a tape with a ferromagnetic substrate around different core materials.

Taking into account the $I_{c}$ curves of a $S u$ bare tape measured as a function of the perpendicular component of magnetic flux density with respect to the surface of the tape at different temperatures, the load lines of the $S u \_M G \_26$ and $S u \_F G_{-} 34$ coils are obtained at different coil operating currents and shown in Fig. 16. At the intersection point of the load line with the $I_{c}-B_{\text {perpendicular }}$ curve at $77 \mathrm{~K}$, the coil $I_{c}$ value is obtained: the simulation and experimental results are in good agreement. This plot is then a useful tool for estimating the $I_{c}$ of the coil at LN2 temperature range. As can be seen, when the temperature changes from $77 K$ to $65 K$ the $\mathrm{I}_{c}$ of the $S u \_M G \_26$ coil increases almost $100 \%$ as does the $\mathrm{I}_{\mathrm{c}}$ of the Su_FG_34.

\section{CONCLUSION}

To investigate how a superconducting and SMC materials can influence the rotating electrical machine performances, circular HTS coils with a double-pancake configuration and with different parameters such as tape material, number of turns, core configuration (fixed and movable), and core material ( $G 10$ and $S M C$ ), were wound and characterized in the ENEA laboratories. Critical current and AC transport current losses of each coil were measured at LN2 temperature by an electrical method. A simulation study was also carried out to estimate the magnetic flux density components, $B_{\text {axial }}$ and

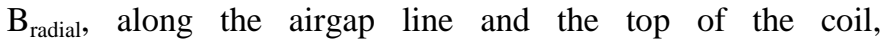
respectively. Based on the simulation and experimental results, it can be concluded that the $S M C$ materials are suitable in the movable core configuration because they allow changing $\mathrm{B}_{\text {axial }}$ and $\mathrm{B}_{\text {radial }}$ without significant reduction of the critical current or increasing the coil power dissipation. Among the different coil options, the one made with GdBCO tape offers a very low AC loss level, at the same current carried, which makes it a great option for electric machines, especially in electric aircraft applications. On the other hand, as this tape is very delicate and brittle compared to the YBCO tape with a ferromagnetic substrate, it is not a recommended option for electrical machines with high Lorentz force. Since the torque and power of rotating machines are proportional to the square of the magnetic flux density, adding an SMC core to the coil helps to increase the magnetic field in the airgap. Therefore, HTS coils with a medium turn number, wound over an $S M C$ core material in the movable core configuration, are recommended for rotating electric machine applications.

\section{ACKNOWLEDGEMENT}

The authors express their gratitude to F. Maierna, M. Marchetti, and G. De Marzi (ENEA for EUROfusion, Frascati, Italy) for their help during experiments.

\section{REFERENCES}

[1] M. Yazdani-Asrami, M. Zhang, and W. Yuan, "Challenges for developing high temperature superconducting ring magnets for rotating electric machine applications in future electric aircrafts," Journal of Magnetism and Magnetic Materials, Early access, 2020.

[2] M. Yazdani-Asrami, M. Staines, G. Sidorov, M. Davies, J. Bailey, N. Allpress, N. Glasson, and S. Asghar Gholamian, "Fault current limiting HTS transformer with extended fault withstand time," Supercond. Sci. Technol., vol. 32, no. 3, pp. 1-13, January 2019. 
[3] F. Weng, M. Zhang, T. Lan, Y. Wang, and W. Yuan, Fully superconducting machine for electric aircraft propulsion: study of AC loss for HTS stator, Supercond. Sci. Technol., vol. 33, no. 10, pp. 1-10, 2020.

[4] W. Song, X. Pei, X. Zeng, M. Yazdani-Asrami, X. Fang, J. Fang, and Z. Jiang, AC Losses in Noninductive SFCL Solenoidal Coils Wound by Parallel Conductors, IEEE Trans. Appl. Supercond., vol. 30, no. 8, pp. 19, 2020.

[5] K. S. Haran, S. Kalsi, T. Arndt, H. Karmaker, R. Badcock, B. Buckley, T. Haugan, M. Izumi, D. Loder, J. W. Bray, P. Masson, and E. W. Stautner, "High Power Density Superconducting Machines Development Status and Technology Roadmap," Supercond. Sci. Technol., vol. 30, no. 12, pp. 1-30, 2017.

[6] Y. Terao, Y. Ishida, H. Ohsaki, and H. Oyori, "Electromagnetic Characteristic Comparison of Superconducting Synchronous Motor Characteristics for Electric Aircraft Propulsion Systems," SAE Int. J. Adv. \& Curr. Prac. in Mobility, vol. 2, no. 2, pp. 828-837, 2020.

[7] M. Zhang, F. Eastham, and W. Yuan, "Design and Modeling of 2G HTS Armature Winding for Electric Aircraft Propulsion Applications," IEEE Trans. Appl. Supercond., vol. 26, no. 3, pp. 1-5, 2016.

[8] S. S. Kalsi, K. Weeber, H. Takesue, C. Lewis, H. W. Neumueller, and R. D. Blaugher, "Development status of rotating machines employing superconducting field windings," Proc. IEEE, vol. 92, no. 10, pp. 16881704, 2004.

[9] C. Gelinas, and S. Pelletier, "Properties and processing of improved SMC materials" in Proc. 2005 Intl. Conf. Powder Metallurgy and 190 Particulate Materials, 2005.

[10] A. Schoppa, and P. Delarbre, "Soft Magnetic Powder Composites and Potential Applications in Modern Electric Machines and Devices," IEEE Trans. Magn., vol. 50, no. 4, pp. 1-4, 2014.

[11] F. Marignetti, On Liquid-Nitrogen-Cooled Copper-Wound Machines With Soft Magnetic Composite Core, IEEE Trans. Ind. Appl., vol. 46, no. 3, pp. 984 - 992, 2010.

[12] Y. Wang, J. Lu, C. Liu, G. Lei, Y. Guo, and J. Zhu, "Development of a High-Performance Axial Flux PM Machine with SMC Cores for Electric Vehicle Application," IEEE Trans. Magn., vol. 55, no. 7, pp. 1-4, 2019.

[13] X. Yu, Y. Li, Q. Yang, C. Zhang, Y. Liu, and X. Gong, "Research of Harmonic Effects on Core Loss in Soft Magnetic Composite Materials," IEEE Trans. Magn., vol. 55, no. 2, pp. 1-5, 2019.

[14] G. Messina, L. Morici, G. Celentano, M. Marchetti, and A. Della Corte, "REBCO Coils System for Axial Flux Electrical Machines Application: Manufacturing and Testing," IEEE Trans. Appl. Supercond., vol. 26, no. 3, pp. 1-4, 2016.

[15] G. Messina, E. T. De Bella, and L. Morici, "HTS Axial Flux Permanent Magnets Electrical Machine Prototype: Design and Test Results," IEEE Trans. Appl. Supercond., vol. 29, no. 5, pp. 1-5, 2019.

[16] G. Messina, L. Morici, U. Besi Vetrella, G. Celentano, M. Marchetti, R. Viola, and P. Sabatino, "AC Loss Measurements of a Trapezoidal Shaped HTS Coil Using an Electrical Method," Int. J. Supercond., vol. 2014, pp. 1-6, 2014.

[17] G. Messina, L. Morici, U. Besi Vetrella, G. Celentano, M. Marchetti, P. Sabatino, and R. Viola, "AC Transport Current Losses in HTS Coils for Axial Flux Electrical Machines Applications," IEEE Trans. Appl. Supercond., vol. 24, no. 3, pp. 1-4, 2014.

[18] M. Furuse, H. Tanaka, J. Kondoh, and M. Umeda, "Experimental Study on AC Loss Reduction of HTS Coils by Use of Ferromagnetic Disks," IEEE Trans. Appl. Supercond., vol. 14, no. 2, pp. 1-4, June 2004.

[19] D. H. N. Dias, G. G. Sotelo, F. J. M. Dias, L. M. M. Rocha, F. G. R. Matins, F. Sass, and A. Polasek, "Characterization of a Second Generation HTS Coil for Electrical Power Devices," IEEE Trans. Appl. Supercond., vol. 25, no. 3, pp. 1-4, 2015.

[20] Y. Jiang, J. X. Jin, Z. Q. Jiang, Y. Yang, S. Duan, Y. Ren, H. Cai, M. Kuang, and J. Wu, "Winding and Testing of YBCO Coils Using Different HTS Wires," IEEE Trans. Appl. Supercond., vol. 26, no. 7, pp. $1-4,2015$.

[21] M. Yazdani-Asrami, W. Song, X. Pei, M. Zhang, and W. Yuan, "AC Loss Characterization of HTS Pancake and Solenoid Coils Carrying Nonsinusoidal Currents," IEEE Trans. Appl. Supercond., vol. 30, no. 5, pp. 1-9, 2020.

[22] S. Yazaki, A. Karasawa, T. Kotoyori, A. Ishiyama, and N. Miyahara, "Critical Current Degradation in High-Temperature Superconducting Tapes Caused by Temperature Rise," IEEE Trans. Appl. Supercond., vol. 23, no. 3, pp. 1-4, 2013.

[23] A. Korpela, T. Kalliohaka, J. Lehtonen, R. Mikkonen, J. Pitel, and P. Kovak, "Current-voltage characteristics of an HTS coil having a hot spot," IEEE Trans. Appl. Supercond., vol. 12, no. 1, pp. 1438-1441, 2002.

[24] I. Kesgin, Q. Hasse, Y. Ivanyushenkov, and U. Welp, "Performance of 2G-HTS REBCO Undulator Coils Impregnated Epoxies Mixed With Different Fillers," IEEE Trans. Appl. Supercond., vol. 24, no. 4, pp. 1-4, 2017

[25] M. Yazdani-Asrami, M. Staines, G. Sidorov, and A. Eicher, "Heat transfer and recovery performance enhancement of metal and superconducting tapes under high current pulses for improving fault current-limiting behavior of HTS transformers," Supercond. Sci. Technol., vol. 33, no. 9, pp. 1-18, 2020.

[26] C. Barth, N. Bagrets, K. P. Weiss, C. M. Bayer, and T. Bast, "Degradation free epoxy impregnation of REBCO coils and cables," Supercond. Sci. Technol., vol. 26, no. 5, pp. 1-10, 2013.

[27] S. Yin, M. Duranti, C. A. Swenson, P. Li, L. Ye, X. Zhang, and T. Shen, "Degradation of REBCO coated conductors due to a combination of epoxy impregnation, thermal cycles, and quench: Characteristics and a method of alleviation," J. Appl. Physc., vol. 128, pp. 1-11, 2020.

[28] D. Yu, Y. Sun, H. Zhang, Y. Meng, and H. Liu, "Experimental Analysis of Critical Current and Alternating Current Losses of High-Temperature Superconductor Tape with Resin and Gallium-Indium-Tin," Materials, vol. 11, no. 573, pp. 1-8, 2018.

[29] A. B. Nunez-Chico, E. Martinez, L. A. Angurel, and R. Navarro, "Effects of Thermal Cycling and Thermal Stability on 2G HTS Pancake Coils," IEEE Trans. Appl. Supercond., vol. 25, no. 3, pp. 1-4, 2015.

[30] M. Oomen, W. Herkert, D. Bayer, P. Kummeth, W. Nick, and T. Arndt, "Manufacturing and test of 2G-HTS coils for rotating machines: Challenges, conductor requirements, realization," Physica C, vol. 482, pp. 111-118, 2012.

[31] T. Takematsu, R. Hua, T. Takao, Y. Yanagisawa, H. Nakagome, D. Uglietti, T. Kiyoshi, M. Takahashi, and H. Maeda, "Degradation of the performance of a YBCO-coated conductor double pancake coil due to epoxy impregnation," Physica C, vol. 470, pp. 674-677, 2010.

[32] M. Yazdani-Asrami, W. Song, M. Zhang, W. Yuan, and X. Pei, "AC Transport Loss in Superconductors Carrying Harmonic Current With Different Phase Angles for Large-Scale Power Components," IEEE Trans. Appl. Supercond., vol. 31, no. 1, pp. 1-5, 2021.

[33] J. Pelegrin, E. Martinez, L. A. Angurel, R. Lahoz, D. Hazelton, P. Brownsey, and J. Duval, "Influence of the Surface Layer on $\mathrm{YBaCuO}$ Coated Conductors Quench Processes," IEEE Trans. Appl. Supercond., vol. 23, no. 3, pp. 1-4, 2013.

[34] Q. Zhang, Y. Yang, E. Young, L. Cavalucci, A. Kario, W. Goldacker, A. Usoskin, and L. Bottura, "Performance and Quench Characteristics of a Pancake Coil Wound With the $2 \mathrm{G}$ YBCO Roebel Cable," IEEE Trans. Appl. Supercond., vol. 28, no. 4, pp. 1-5, 2018.

[35] S. Dai, T. Zhang, S. Mo, Y. Cai, W. Yuan, T. Ma, L. Hu, and B. Wang, "Study on Preparation, Thermal Conductivity and Electrical Insulation Properties of Epoxy/AIN," IEEE Trans. Appl. Supercond., vol. 29, no. 2, pp. 1-6, 2019.

[36] M. Yazdani-Asrami, S. Asghar Gholamian, S. M. Mirimani, and J. Adabi, "Investigation on effect of magnetic field dependency coefficient of critical current density on the AC magnetizing loss in HTS tapes exposed to external field," J. Supercond. Novel Magnetism, vol. 31, no. 12, pp. 3899-3910, 2018.

[37] W. Song, Z. Jiang, X. Zhang, M. Staines, R. A. Badcock, J. Fang, Y. Sogabe, and N. Amemiya, "AC loss simulation in a HTS 3-Phase 1 MVA transformer using $H$ formulation," Cryogenics, vol. 94, pp. 14-21, 2018.

[38] M. Yazdani-Asrami, S. Asghar Gholamian, S. M. Mirimani, and J. Adabi, "Calculation of AC Magnetizing Loss of ReBCO Superconducting Tapes Subjected to Applied Distorted Magnetic Fields," J. Supercond. Novel Magnetism, vol. 31, no. 12, pp. 3875-3888, 2018.

[39] M. Yazdani-Asrami, M. Taghipour-Gorjikolaie, W. Song, M. Zhang, and W. Yuan, "Prediction of nonsinusoidal AC loss of superconducting tapes using Artificial Intelligence-based models," IEEE Access, vol. 8, pp. 207287-207297, 2020.

[40] M. D. Ainslie et al., "An improved FEM model for computing transport AC loss in coils made of RABiTS YBCO coated conductors for electric machines", Supercond. Sci. Technol., vol. 24, 2011, 045005. 